\title{
Aspectos clínicos da premunição contra Babesia (Starcovici, 1893) e Anaplasma (Theiler, 1910) em bovinos da raça Simental
}

\section{Clinical aspects of premunition measures against Babesia (Starcovici, 1893) and Anaplasma (Theiler, 1910) in Simental bovines}

\author{
Flávio Augusto Soares Graça, ${ }^{*}$ Luiz Felipe Castro Graeff Vianna, ${ }^{\star \star}$ Paulo César Amaral Ribeiro da Silva, ${ }^{\star \star \star}$ \\ José Renato Junqueira Borges ${ }^{\star \star \star *}$
}

\begin{abstract}
Resumo
Trinta e oito fêmeas Bos taurus da raça Simental com idade variando entre 1 e 4 anos, importadas da Áustria e da Alemanha, foram submetidas ao processo de premunição no município de Aracruz, Estado do Espírito Santo. Foram utilizados $0,6 \mathrm{ml}$ de um inóculo de Babesia bigemina compreendendo 1,8 $\times 10^{8}$ hemácias parasitadas por $\mathrm{ml}$ de sangue, 1,0 ml de um inóculo de Babesia bovis com 1,0 X $10^{8}$ hemácias parasitadas por $\mathrm{ml}$ de sangue, ambas atenuadas por passagem em bezerros esplenectomizados e $0,5 \mathrm{ml}$ de um inóculo de Anaplasma marginale contendo $1,2 \times 10^{8}$ hemácias parasitadas por ml de sangue. Além do acompanhamento clínico, foram realizados exames de esfregaço sangüíneo e do volume globular. Quarenta e oito dias após a inoculação, foi realizado o desafio com sangue de animal sorologicamente positivo para $B$. bovis, $B$. bigemina e $A$. marginale. Durante o experimento, foram coletadas três amostras de soro sangüíneo dos animais, nos dias 0,47 e 80 após a inoculação, para realização da prova da imunofluorescência indireta (IFA). O inóculo de $B$. bigemina e $B$. bovis provocou sintomatologia clínica em apenas um animal. $O$ inóculo de $A$. marginale apresentou uma elevada patogenicidade com um período de incubação médio variando de 24 a 26 dias e sete animais apresentaram recidiva. Após o desafio, 26 animais apresentaram sintomatologia de babesiose e o período prepatente variou de 8 a 26 dias após o desafio. Trinta e dois dias após o desafio, todos os animais dos quatro lotes apresentaram títulos acima de 1:320 para Anaplasma marginale, 15 apresentaram títulos negativos e 23 apresentaram títulos acima de 1:40 para. Babesia bigemina e Babesia bovis.
\end{abstract}

Palavras-chave: premunição; babesiose; tristeza parasitária; anaplasmose; Babesia; Anaplasma; bovinos; doenças parasitárias.

\begin{abstract}
Thirty eight female of the Bos taurus species, Simental breed, ages ranging from 2 to 4 years old, imported from Austria and Germany, were subjected to premunition process in the county of Aracruz, Espirito Santo State. Babesia bigemina inoculum have been used with $0,6 \mathrm{ml}$ with $1.8 \times 10^{8} / \mathrm{ml}$ parasitized red blood cells, and Babesia bovis inoculum with $1,0 \mathrm{ml}$ with $1.0 \times 10^{8}$ $/ \mathrm{ml}$ parasitized red blood cells both attenuated through passage in splenectomized calves, and Anaplasma marginale inoculum with $1.2 \times 10^{8}$ parasitized cells $/ \mathrm{ml}$. In addition to clinical accompaniment, packed cell volume and blood smaers were performed. Forty eight days after the innoculation the challenge with blood of seropositive animals for $B$. bovis, $B$. bigemina and $A$. marginale were made. During the experiment, three samples of blood serum from the animals were collected on the days 0,47 and 80 after the innoculation for imunoflorescence assay (IFA). The inoculum with B. bovis and B. bigemina caused clinical sintomatology in only one animal. The inoculum with $A$. marginale showed high pathogenicity with a period of incubation of about 24 to 26 days and seven animals presented recurence. After the challenge, twenty six animals presented sintomatology for babesiose and the incubation period range from 8 to 26 days after the challenge. After the thirty second day of the challenge, all animalls presented titers above 1:320 for Anaplasma marginale, 15 presented negative titers and 23 presented titers above $1: 40$ for B. bigemina and B. bovis.
\end{abstract}

Keywords: premunition, babesiose, anaplasmose, Babesia, Anaplasma, bovine, cattle, parasitary diseases. \footnotetext{
* Prof. Adjunto, Faculdade de Medicina Veterinária da Fundação Educacional Dom André Arcoverde - FAA, Rua Sargento Victor Hugo, 161, Bairro
de Fátima, CEP 27600-000 - Valença, RJ.

** Prof. Titular, Departamento de Medicina e Cirurgia, Instituto de Veterinária, UFRRJ, Seropédica, RJ.

*** Prof. Adjunto, Faculdade de Medicina Veterinária da Fundação Educacional Dom André Arcoverde

**** Prof. Titular, Faculdade de Veterinária, Universidade Federal Fluminense, Niterói, RJ.
} 


\section{Introdução}

A babesiose e a anaplasmose bovina, também conhecidas no Brasil como Tristeza Parasitária, Febre dos Carrapatos ou "Tristeza", são hemoparasitoses comumente encontradas nas áreas tropicais e subtropicais do mundo onde existem carrapatos. Essas enfermidades são responsáveis por provocarem a perda de peso, queda na produção de leite, de carne e influenciam negativamente na reprodução, além da alta taxa de mortalidade, causando grandes prejuízos à bovinocultura (Emerson et al., 1974; Todorovic, 1975; Massard, 1990).

Mahoney (1977), citado por Kreier (1977), afirmou que a imunização contra a babesiose consiste na transmissão da doença a animais susceptíveis através da inoculação de sangue infectado e do subseqüente tratamento com droga babesicida para prevenção contra o agravamento da doença e morte do animal. Disse ainda que o maior problema para profilaxia está na padronização da vacina, devido ao número de cepas e suas diferentes virulências. A atenuação da $B$. bovis (Babés, 1888) por contínuas passagens em bezerros esplenectomizados tem-se mostrado um método de padronização de um inóculo usando $10^{7}$ organismos por dose, que causa uma reação menos severa ao animal, sendo rara a necessidade de tratamento.

A despeito dos estudos para o desenvolvimento de vacinas, sejam elas feitas com Anaplasma centrale ou vacina morta de Anaplasma marginale (Theiler, 1910), seus resultados ainda são contraditórios, sendo a premunição, quando bem feita, uma medida de alta eficiência na proteção do gado importado, porém o uso do $A$. marginale virulento resulta em $100 \%$ de morbidade e, sem controle laboratorial, pode ocasionar elevada taxa de mortalidade (Corrêa e Corrêa, 1992).

Loss (1991) demonstrou que a utilização do inóculo padronizado congelado é uma opção viável e eficiente para ser empregada no programa de premunição. Além de tornar o período prepatente mais uniforme, permite uma maior programação das atividades e um efetivo controle das doenças transmitidas durante a inoculação.

Entretanto, a premunição no Brasil é ainda realizada de maneira empírica, pois pouco se conhece sobre as alterações que ocorrem durante a premunição em nosso meio (Kohayagawa, 1985).

O presente trabalho tem como objetivo estudar as variações clínicas apresentadas por bovinos da raça Simental durante o processo de premunição, buscando com isso, delinear parâmetros que possam contribuir para a segurança e eficácia deste método de prevenção.

\section{Material e métodos}

A premunição foi realizada no município de Aracruz, estado do Espírito Santo, no período de 1 de fevereiro a 20 de abril de 1995, em 38 fêmeas da raça Simental, com idade variando entre 13 e 48 meses, procedentes da Alemanha e Áustria. Vinte e quatro se encontravam prenhes no terço médio e final da gestação.

Os animais foram embarcados na Bélgica no dia 19 de janeiro de 1995, quando a temperatura ambiente média era de $-18^{\circ} \mathrm{C}$ e chegaram ao Brasil, desembarcando no dia 20 de janeiro de 1995 , quando a temperatura média era de $30^{\circ} \mathrm{C}$. Após o desembarque, foi fornecida água para os animais e as fêmeas em lactação foram ordenhadas. Depois, os animais foram embarcados em um caminhão para dar continuidade à viagem ao município de Aracruz, situado a $500 \mathrm{~km}$ de Belo Horizonte.

No dia 21 de janeiro de 1995 , os animais, ao chegarem à fazenda, foram acomodados em uma instalação de concreto do tipo free stall a qual confere a possibilidade de um isolamento de outros animais ou de pastagens com presença de carrapatos. Vinte quatro horas após a chegada, os animais foram submetidos a um exame clínico, foram coletadas fezes de $15 \%$ dos animais para exame coproparasitológico, além de sangue venoso de todos, para obtenção de soro.

Durante toda a premunição, os animais receberam uma alimentação padronizada, à base de feno de capim "Coastcross" (Cynodon nlefuesens X Cynodon dactilun), capim-elefante (Pennisetum purpureum), concentrado, além de uma mistura mineral e água à vontade.

Os animais foram submetidos a um período de aclimatação e descanso durante 10 dias e foram tosquiados a fim de diminuir o estresse calórico.

Foram realizados uma inoculação e um desafio. A primeira, no dia 1 de fevereiro de 1995, com inóculos elaborados pelo professor José Divino Lima, da Universidade Federal de Minas Gerais, a partir do sangue de bezerros esplenectomizados, sorologicamente negativos para leucose, brucelose, leptospirose, diarréia bovina a vírus e rinotraqueíte infecciosa bovina, infectados com B. bigemina (Smith e Kilborne, 1893), $B$. bovis e $A$. marginale. Este inóculo foi padronizado com as seguintes concentrações:

a) $1,2 \times 10^{8}$ hemácias parasitadas com $A$. marginale por $\mathrm{ml}$ de sangue, sendo inoculado $0,5 \mathrm{ml}$ por animal por via subcutânea;

b) $1,8 \times 10^{8}$ hemácias parasitadas com $B$. bigemina por $\mathrm{ml}$ de sangue, sendo inoculado 0,6 ml por animal por via subcutânea;

c) 1,0 $010^{8}$ hemácias parasitadas com $B$. bovis por $\mathrm{ml}$ de sangue, sendo inoculado $1,0 \mathrm{ml}$ por animal por via subcutânea.

Até o momento da inoculação, o inóculo foi transportado e mantido em nitrogênio líquido a uma temperatura de $-196^{\circ} \mathrm{C}$.

O desafio foi realizado 48 dias após a inoculação, utilizandose sangue venoso em citrato de sódio e dextrose, mantido sob refrigeração. $O$ sangue foi obtido através da punção da veia jugular de uma vaca adulta da raça Simental, criada na região, sorologicamente positiva para $B$. bigemina, $B$. bovis e $A$. marginale e sorologicamente negativa para brucelose, tuberculose, leucose bovina, rinotraqueíte bovina infecciosa e diarréia viral bovina. Foram inoculados $5 \mathrm{ml}$ de sangue, por via subcutânea, em cada animal.

Durante os 80 dias de premunição, foram coletadas amostras de sangue de vasos da extremidade da cauda de todos os animais a cada 48 horas para confecção de esfregaços sangüíneos, objetivando a pesquisa de hemoparasitas. Os animais que se apresentavam em fase clínica da enfermidade eram examinados diariamente. Os esfregaços foram corados pelo Giemsa e observados em microscópio óptico, em objetiva de imersão. A parasitemia para $A$. marginale foi calculada a partir da contagem de cinco campos de 100 hemácias 
e expressa em percentagem de hemácias parasitadas. Além da parasitemia, durante a hematoscopia outros elementos eram observados para melhor avaliação clínica do animal, como a presença de reticulócitos.

A temperatura retal dos animais foi registrada de 12 em 12 horas, começando no dia seguinte à chegada dos animais, até o $80^{\circ}$ dia após a data da inoculação.

Cada animal teve seu volume globular determinado antes da inoculação e a partir da mesma, registrado a cada 96 horas, durante os 80 dias após a inoculação. Durante a fase clínica da doença, o volume globular dos animais era acompanhado diariamente. Foi usada a técnica de microhematócrito, com coleta de sangue da veia marginal da orelha.

Todos os animais foram tratados de acordo com a necessidade estabelecida a partir dos seguintes parâmetros: animal que apresentava no exame de esfregaço sangüíneo a presença de hemácias parasitadas por Babesia sp. e queda do volume globular, foi medicado com $3.5 \mathrm{mg} / \mathrm{kg}$ p.v. de diaceturato de 4,4 diazoaminodibenzamidina, ${ }^{1}$ por via intramuscular profunda em dose única; o animal que apresentava no exame do esfregaço presença de parasitemia a partir de 1,0\% para A. marginale foi medicado com $10 \mathrm{mg} / \mathrm{kg}$ p.v. de cloridrato de oxitetraciclina, ${ }^{2}$ por via endovenosa a cada 24 horas, durante três dias e, no quarto dia, com uma dose de $20 \mathrm{mg} / \mathrm{kg}$ p.v. de oxitetraciclina em veículo oleoso ${ }^{3}$ por via intramuscular profunda.

Para a prova de imunofluorescência indireta foram coletadas amostras de sangue venoso dos animais para obtenção de soro antes da inoculação e 47 e 80 dias após a mesma. As amostras de soro foram estocadas a $-18^{\circ} \mathrm{C}$ durante a premunição para serem analisadas ao final da mesma. Os soros sofreram diluições múltiplas em solução salina tamponada (PBS, pH 7,2) a partir de 1:40.

\section{Resultados}

Dos 38 animais integrantes, 24 estavam prenhes e apenas 11 não mantiveram a sua condição corporal média talvez, pelo fato de terem abortado. Dos 11 abortamentos, quatro ocorreram no terço médio da gestação e sete no terço final. Além dos abortamentos acontecidos durante o experimento, outras patologias ocorreram com os animais como: hipertermias, patologias de casco, mastites, traumatismos e estresse.

Após a inoculação, apenas um animal apresentou B. bigemina (com um período prepatente de 17 dias), observada no esfregaço sangüíneo, assim como uma branda sintomatologia da infeção.

Durante o período compreendido entre a inoculação e o desafio, o período de incubação médio para $A$. marginale variou de 24 a 26 dias e o período prepatente individual foi mínimo de 21 e máximo de 32 dias. A parasitemia para $A$. marginale, no início do tratamento, foi mínima de $1 \%$ e máxima, de $15 \%$. A média das parasitemias, no início do tratamento, foi de $5,5 \%$. A parasitemia máxima para $A$. marginale foi de $25 \%$ em um animal, sendo que a média das máximas foi de $8,5 \%$. Dos 38 animais, sete apresentaram recidiva de anaplasmose, sendo que o animal que apresentou a percen-

1 Ganaseg - Ciba Geigy Química S.A.

2 Talcin Injetável - Ciba Geigy Química S.A.

3 Terramicina LA - Labs. Pfizer Ltda. tagem máxima de parasitemia após a inoculação manifestou duas recidivas com 39 e 66 dias após a inoculação (DAl).

Após o desafio, 26 dos 38 animais apresentaram esfregaço positivo para $B$. bigemina e o período prepatente variou de oito a 26 dias após o desafio (DAD).

Apenas quatro animais apresentaram, após o desafio, $A$. marginale detectados nos esfregaços, em percentagem máxima de $0,75 \%$, não ocorrendo sintomatologia clínica ou necessidade de tratamento.

Os períodos prepatentes para $A$. marginale, o início dos tratamentos e os animais que apresentaram recidivas estão apresentados na Tabela 1.

Tabela 1: Período prepatente para Anaplasma marginale e tratamento dos animais, submetidos ao processo de premunição com inóculo.

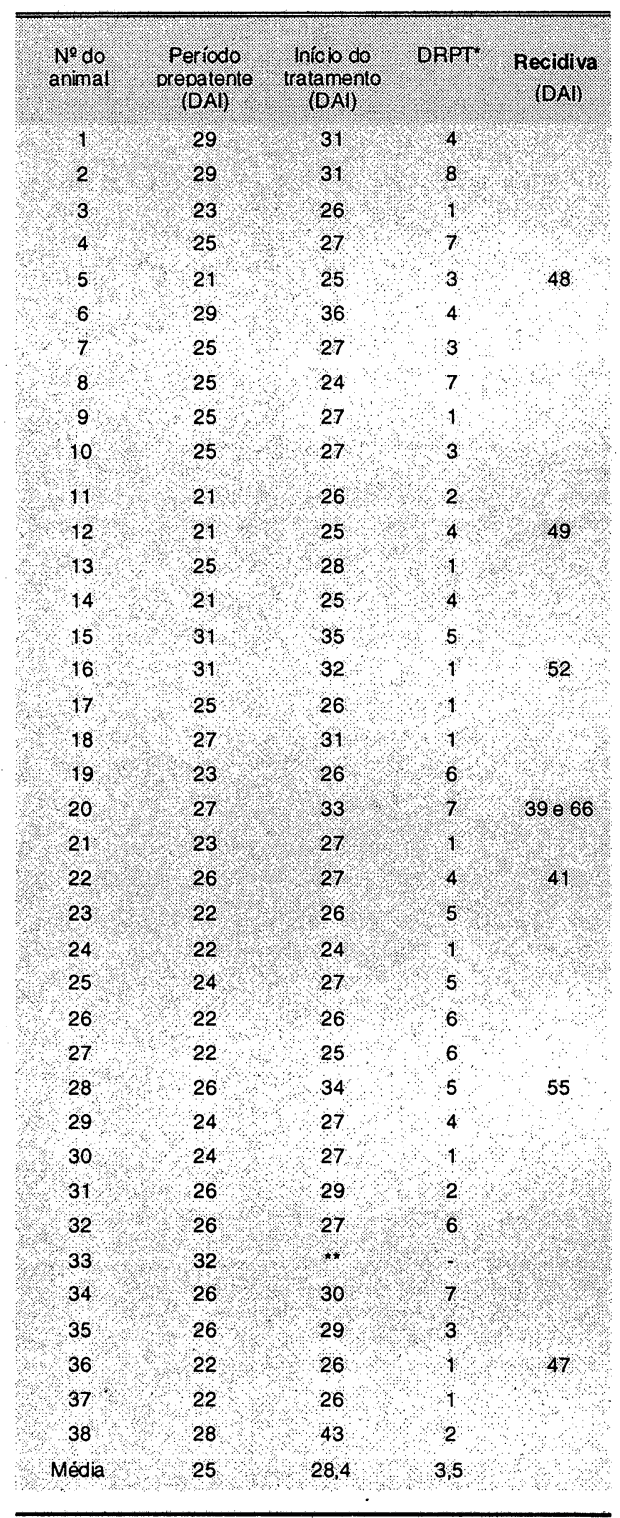

* Dias para redução da parasitemia após início do tratamento. ${ }^{\star \star}$ Animal não adoeceu. 


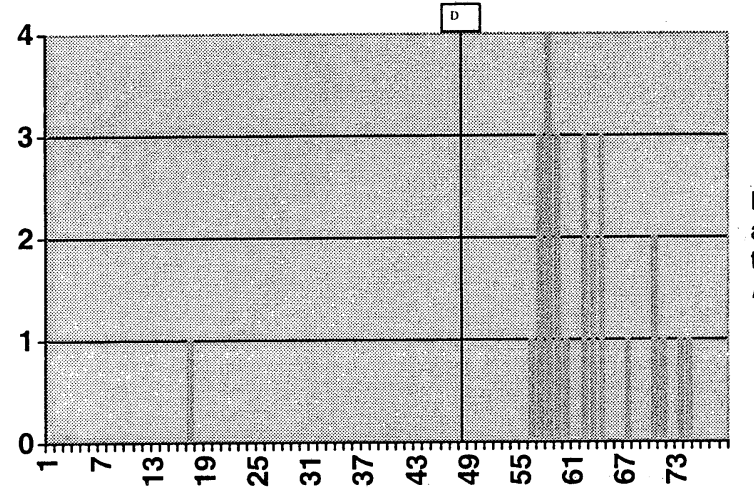

Figura 1: Número de animais que apresentaram parasitemia para Babesia.
Durante a premunição não foram identificadas $B$. bovis no esfregaço de sangue periférico. Apenas um animal apresentou esfregaço sangüíneo positivo para $B$. bigemina no $17^{\circ} \mathrm{DAl}$. O número de animais e respectivos dias com esfregaços positivos para $B$. bigemina após o desafio, estão expressos na Figura 1. Os períodos prepatentes dos animais estão apresentados na Tabela 2.

Foram observados reticulócitos nos esfregaços sangüíneos de 28 dos 38 animais a partir do $31^{\circ}$ até $\circ 46^{\circ} \mathrm{DAl}$. Apenas quatro animais apresentaram retículócitos a partir do $9^{\circ}$ até o $12^{\circ}$ dia.

As médias das parasitemias para $A$. marginale estão expressas na Figura 2.
Tabela 2: Período pre-patente para Babesiose dos animais, submetidos ao desafio com sangue

\begin{tabular}{|c|c|}
\hline$N^{\circ}$ do animal & $\begin{array}{l}\text { Periodo } \\
\text { prepatente (DAD) }\end{array}$ \\
\hline 1 & 14 \\
\hline 2 & 14 \\
\hline 3 & 16 \\
\hline 4 & 8 \\
\hline 5 & 22 \\
\hline 6 & $*$ \\
\hline 7 & $x$ \\
\hline 8 & 10 \\
\hline 9 & 26 \\
\hline 10 & + \\
\hline 11 & 12 \\
\hline 12 & + \\
\hline 13 & 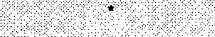 \\
\hline 14 & 22 \\
\hline 15 & 10 \\
\hline 16 & 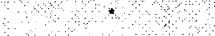 \\
\hline 17 & 14 \\
\hline 18 & 16 \\
\hline 19 & $*$ \\
\hline 20 & $*$ \\
\hline 21 & 11 \\
\hline 22 & $\cdot$ \\
\hline 23 & 11 \\
\hline 24. & 11 \\
\hline 25 & 9 \\
\hline 26 & 9 \\
\hline 27 & 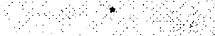 \\
\hline 28 & 23 \\
\hline 29 & + \\
\hline 30 & 10 \\
\hline 31 & 8 \\
\hline 32 & 15 \\
\hline 33 & 9 \\
\hline 34 & 10 \\
\hline 35 & 19 \\
\hline 36 & 15 \\
\hline 37 & 16 \\
\hline 38 & 25 \\
\hline Media. & 14,5 \\
\hline
\end{tabular}

* Animais não adoeceram.

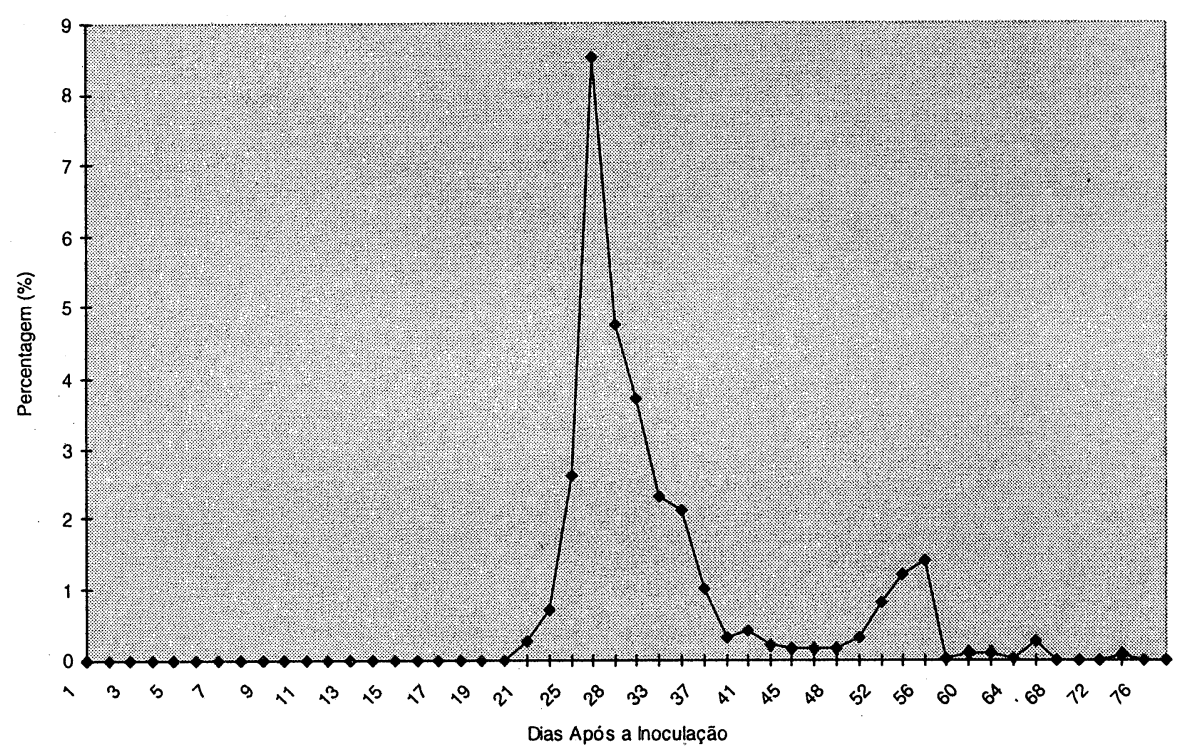

Figura 2: Média das parasitemias de Anaplasma marginale

A temperatura retal média dos animais foi mensurada durante cinco dias que precederam a inoculação e variou entre 38,65 e $38,95^{\circ} \mathrm{C}$ no período da manhã e de 39,44 a $40,01^{\circ} \mathrm{C}$ no período da tarde.

Entre o primeiro e o quinto DAI não ocorreram variações acima dos valores citados.

Do quinto ao $15^{\circ} \mathrm{DAl}$, a temperatura variou de 38,70 a $39,76^{\circ} \mathrm{C}$ no período da manhã e 39,36 e $40,35^{\circ} \mathrm{C}$ no período da tarde.

Durante a fase de parasitemia do $A$. Marginale, que teve início no $21 \% \mathrm{DAl}$, a temperatura variou de 38,64 a $39,75^{\circ} \mathrm{C}$ no período da manhã e 38,91 a $40,70^{\circ} \mathrm{C}$ no período da tarde.

Após o desafio e durante a fase de parasitemia de Babesia sp., os animais apresentaram uma temperatura média que variou de 38,74 a $39,50^{\circ} \mathrm{C}$ no período da manhã e 39,10 a $40,18^{\circ} \mathrm{C}$ no período da tarde.

As médias das temperaturas retais estão expressas na Figura 3.

Antes da inoculação, o valor médio do V.G. era de 31,8\%. Apenas a partir da fase parasitêmica de anaplasmose após a inoculação, estes valores apresentaram um decréscimo substancial, sendo que o percentual médio de redução foi de $37,4 \%$ e o valor mínimo ocorreu aproximadamente, $32 \mathrm{DAl}$.

O valor médio do V.G.dos 38 animais dois dias antes do desafio era de $23,4 \%$. O valor médio mínimo do V.G., após o desafio, foi de $22,50 \%$ sendo que este valor ocorreu em média 9,3 DAD. 
Tabela 3: Parasitemia para Anaplasma marginale dos animais, submetidos ao processo de premunição com inóculo.

\begin{tabular}{|c|c|c|c|c|}
\hline$N^{\circ}$ do animal & & Parasi & nia $(\%)$ & \\
\hline & $\begin{array}{l}\text { Inicio do } \\
\text { tratamento }\end{array}$ & Máxima & $\begin{array}{l}\text { Final do } \\
\text { Tratamento }\end{array}$ & Recidiva \\
\hline 1 & 2,5 & 3 & 2,5 & \\
\hline 2 & 2,5 & 4 & 4 & \\
\hline 3 & 3 & 10 & 10 & \\
\hline 4 & 2 & 6 & 3 & \\
\hline 5 & 12 & 20 & 15 & 2 \\
\hline 6 & 2 & 4 & 0,25 & \\
\hline 7 & 4 & 15 & 7 & \\
\hline 8 & 1 & 5 & 5 & \\
\hline 9 & 6 & 6 & 3 & \\
\hline 10 & 2,5 & 3 & 1,5 & \\
\hline 11 & 5 & 15 & 10 & \\
\hline 12 & 10 & 15 & 15 & 2,5 \\
\hline 13 & 2,5 & 3 & 1,5 & \\
\hline 14 & 10 & 10 & 10 & \\
\hline 15 & 3,5 & 12 & 10 & \\
\hline 16 & 1 & 1 & 1 & 6 \\
\hline 17 & 7 & 7 & 4 & \\
\hline 18 & 8 & 8 & 4 & \\
\hline 19 & 3,5 & 6 & 4 & \\
\hline 20 & 5 & 25 & 8 & 25 \\
\hline 21 & 15 & 15 & 12 & \\
\hline 22 & 2,5 & 5,5 & 2,5 & \\
\hline 23 & 10 & 13 & 13 & 2 \\
\hline 24 & 3 & 3 & 2,5 & \\
\hline 25 & 5 & 6 & 6 & \\
\hline 26 & 8 & 8 & 7 & \\
\hline 27 & 10 & 15 & 10 & \\
\hline 28 & 4 & 12 & 12 & \\
\hline 29 & 15 & 15 & 15 & \\
\hline 30 & 12 & 12 & 4 & \\
\hline 31 & 1,5 & 2 & 0.5 & 1,5 \\
\hline 32 & 2,5 & 6 & 3,5 & \\
\hline 33 & * & 1 & ? & \\
\hline 34 & 2,5 & 3,5 & 2,5 & \\
\hline 35 & 2 & 3 & 1 & \\
\hline 36 & 10 & 10 & 3 & 4,5 \\
\hline 37 & 5 & 5 & 2,5 & \\
\hline 38 & 5 & 9 & 7 & \\
\hline Média & 5.5 & 8.5 & 5.9 & \\
\hline
\end{tabular}

* Não houve tratamento.

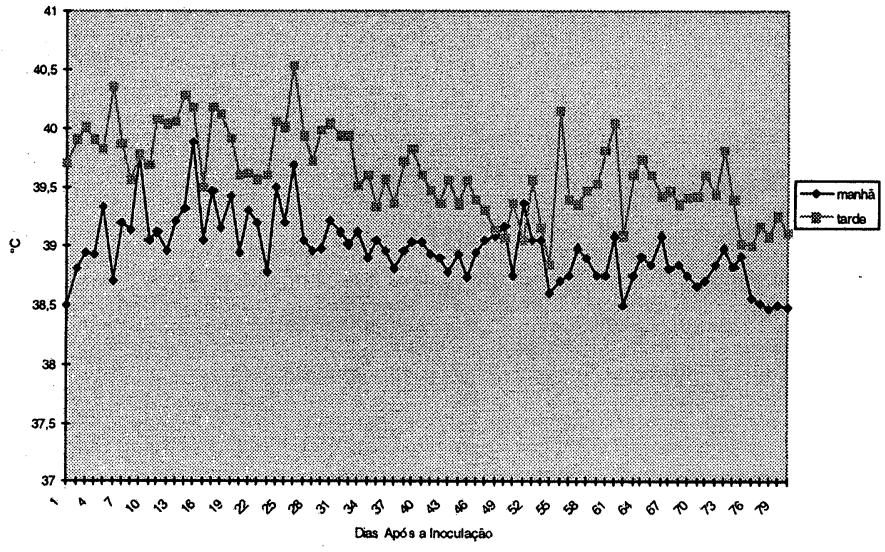

Figura 3: Variação média das temperaturas durante a premunição .

A média do V.G. dos 38 animais está expressa na Figura 4. Os animais em fase anaplásmica foram tratados com uma parasitemia inicial mínima de $1 \%$ e máxima de $15 \%$, com cloridrato de oxitetraciclina, e observou-se que o início da queda da parasitemia média foi de 3,5 dias (Tabela 1). Não houve mortalidade.

Tabela 4: Valores médios de volume globular e percentual médio de redução (PMR) dos animais, submetidos ao processo de premunição por Babesia bigemina, B. bovis e Anaplasma marginale.

\begin{tabular}{|c|c|c|c|}
\hline \multirow{3}{*}{$\begin{array}{c}N^{0} \text { de animais } \\
38\end{array}$} & Antes da & \multicolumn{2}{|c|}{ Após inoculação } \\
\hline & & Minimo/DAi & PMR \\
\hline & 31,4 & $19,8 / 31,9$ & 37.4 \\
\hline
\end{tabular}

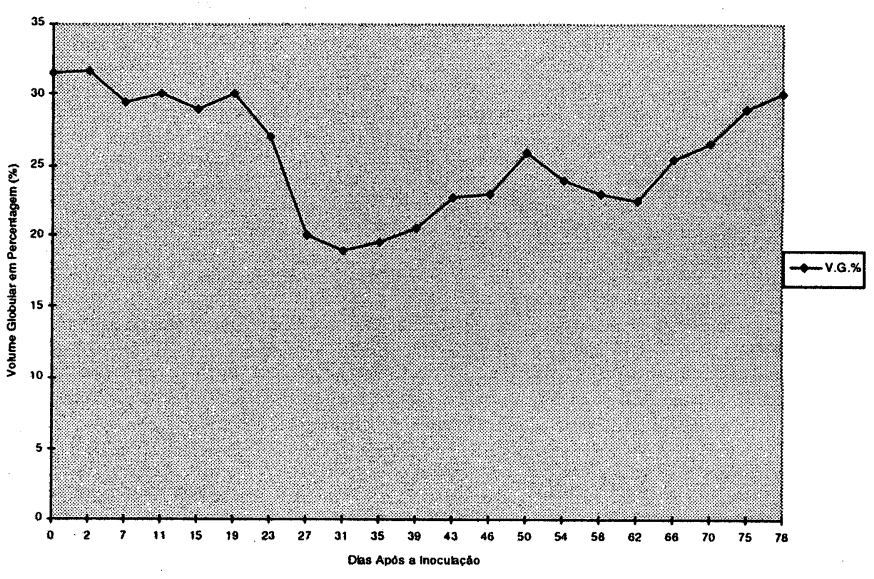

Figura 4: Média de volume globular. 
Tabela 5: Valores médios de volume globular e percentual médio de redução (PMR) dos animais, submetidos ao desafio com sangue.

\begin{tabular}{|c|c|c|c|}
\hline$N^{0}$ de animais & Dois dias & Após desatio & \\
\hline & antes do desafio & Mínimo/DAD & PMR \\
\hline 38 & 23,4 & $22,5 / 9,3$ & 3,75 \\
\hline
\end{tabular}

Todos os animais eram sorologicamente negativos para $A$. marginale, $B$. bigemina e $B$. bovis antes da inoculação, sendo que 47 dias após a mesma, todos os 38 animais (100\%) apresentaram títulos para $A$. marginale que variaram de 1:320 a $1: 2560$. Entretanto, 14 animais $(36,84 \%)$ ainda não tinham títulos de anticorpos para $B$. bigemina e sete $(18,42 \%)$ para $B$. bovis. Em 21 animais $(55,26 \%)$ os títulos para $B$. bovis e $B$. bigemina variaram de 1:40 a 1:320.

No exame realizado $80 \mathrm{DAl}$, todos os 38 animais (100\%) apresentaram títulos positivos para $A$. marginale, $15(39,47 \%)$ não apresentaram títulos para $B$. bigemina e $B$. bovis e 23 $(60,53 \%)$ apresentaram títulos positivos que variaram de 1:40 a $1: 320$, sendo que durante todo o experimento apenas um animal não apresentou títulos positivos para $B$. bovis e $B$. bigemina.

\section{Discussão e conclusões}

Esse experimento foi realizado em um período de 80 dias, tempo inferior ao experimento de Brasil (1982) de 100 dias de duração, de Kohayagawa (1985), que durou 92 dias, e de Loss (1991) de aproximadamente 120 dias e, superior ao realizado por Bangel Junior et al. (1987), que durou 45 dias.

A utilização de amostras atenuadas de $B$. bigemina e $B$. bovis mostrou-se de grande valor na premunição, pois proporcionou um primeiro contato dos animais com esses protozoários, realizado com uma maior margem de segurança e com uma sintomatologia mais atenuada, em acordo com as observações de Gonzales et al. (1976), Mahoney (1977) citado por Kreier(1977) e Loss (1991). O inóculo com A. marginale, embora não fosse atenuado, proporcionou um período prepatente uniforme, proporcionando uma melhor programação das atividades de premunição, concordando com a citação de Loss (1991). A severidade dos sintomas de anaplasmose, após a inoculação, pode ter sido influenciada pelo fato do inóculo não estar atenuado, em acordo com a explicação de Massard (1990).

O inóculo utilizado, assim como o acompanhamento clínico e laboratorial realizado a campo, mostraram compor um método mais técnico que necessita da presença constante do médico veterinário durante a premunição, em comparação com o que emprega o sangue fresco em animais a campo ou estabulados sem um controle tão efetivo como o método de Bangel Junior et al. (1987).

Além da alta temperatura ambiente, outro fator prejudicial foi a ocorrência de abortamentos em $47,8 \%$ dos animais gestantes, confirmando as citações de Emerson et al. (1974) e
Blood e Radostits (1991), o que poderia ter-se evitado se tivessem sido importadas fêmeas jovens que ainda não tivessem iniciado suas atividades reprodutivas ou não gestantes de acordo com Santos (1950).

Após a inoculação, foram observadas manifestações clínicas de intensidade bastante reduzida durante a fase de babesiose, sendo que dos 38 animais, apenas um apresentou resultado positivo no exame do esfregaço de sangue e, desta forma, os animais, embora fossem portadores de Babesia sp., ainda se encontravam em uma situação favorável para suportar o pico de anaplasmose, pois não estavam convalescentes da babesiose, como citaram Corrêa e Corrêa (1992), não necessitando inocular o $A$. marginale antes da Babesia sp. como observou Santos (1950).

O período de incubação médio de 24 a 26 dias para $A$. marginale mostrou-se bastante uniforme e dentro do apresentado por Stephan e Squibel (1929), Brasil (1982), Kohayagawa (1985) e Loss (1991), e superior ao encontrado por Kreier et al. (1964), Todorovic (1975), Todorovic e Tellez (1975), Gonzales et al. (1976), Ajayl et al. (1978) e Otim et al. (1980).

A parasitemia média para $A$. marginale antes do tratamento, foi de $5,5 \%$, sendo superior a parasitemia inicial dos experimentos de Pandey e Misha (1978), Kohayagawa(1985) e Loss (1991), o que ocasionou uma parasitemia máxima média de $8,5 \%$ também superior à encontrada por diversos autores como Hansard e Foot (1959), Kreier et al. (1964), Gonzales et al. (1976), Pandey e Misha (1978), Otim et al. (1980), Kohayagawa (1985) e Loss (1991).

Após o desafio, a variação do período de incubação de 8 a 26 dias para $B$. bigemina foi superior aos experimentos citados Stephan e Squibel (1929), Todorovic (1975), Mahoney (1977) e Kohayagawa (1985), e semelhante ao de Brasil (1982). Essa diferença se deve, provavelmente, ao fato de os animais, ao serem desafiados com sangue, já terem títulos variados de anticorpos contra Babesia sp.

Observando-se a Figura 3 podemos constatar um aumento da temperatura durante a fase de parasitemia de Babesia sp. juntamente com o aparecimento de um caso clínico com identificação de $B$. bigemina em esfregaço sangüíneo. No $11^{\circ}$ dia, a elevação da temperatura ocorreu em niveis semelhantes aos relatados por Callow e Pepper (1974), Emerson et al. (1974) e Kohayagawa (1985).

Foi encontrada uma variação de temperatura mensurada no período da manhã inferior à encontrada no período da tarde. Resultados similares foram apresentados por Todorovic (1975), Kohayagawa (1985) e Loss (1991).

$\mathrm{Na}$ fase clínica de anaplasmose, após a inoculação, foi observado um aumento da média de temperatura dos animais, inferior ao aumento citado na fase de anaplasmose por Emerson et al. (1974) e Kohayagawa (1985).

Durante o desenvolvimento do trabalho, observou-se que a temperatura não deve ser utilizada isoladamente como parâmetro para início do tratamento, já que nem sempre as elevações de temperatura foram acompanhadas de parasitemia por Babesia sp. ou A. marginale. Observações similares foram feitas por Loss (1991). 
Após o desafio, 26 animais apresentaram sintomatologia de babesiose acompanhada de esfregaço positivo para $B$. bigemina e que provocou uma terceira elevação na temperatura média como podemos observar na Figura 3. Esses valores referentes à temperatura foram semelhantes aos citados por Callow e Pepper (1974), Emerson et al. (1974) e Kohayagawa (1985).

Após a inoculação, durante o período de incubação da babesiose, não houve uma redução acentuada do V.G., certamente devido à atenuação das cepas utilizadas no inóculo, não ocorrendo reações tão severas como as relatadas por Todorovic (1975), Todorovic e Telez (1975), Gonzales et al. (1976), Mahoney (1977) citado por Kreier (1977) e Kohayagawa (1985).

Com o início da fase parasitêmica da anaplasmose ocorreu um decréscimo, com um percentual médio de redução da ordem de $37,4 \%$ semelhante ao apresentado por Hansard e Foote (1959), e superior aos encontrados po Jatkar e Kreier (1964), Gonzales et al. (1976), Ajayl et al. (1978), Otim et al. (1980) e Loss (1991), o que provavelmente foi resultado da alta média de parasitemia no início do tratamento.

Após o desafio, com o início da fase parasitêmica de babesiose, o percentual de redução do V.G. foi inferior ao apresentado por Todorovic e Tellez (1975), Gonzales et al. (1976) e Kohayagawa (1985), provavelmente porque nesse período os animais já haviam tido contato com o antígeno após a inoculação e, conseqüentemente, apresentavam já alguma imunidade para Babesia sp. Durante a fase de anaplasmose, após o desafio não houve redução do V.G. por

\section{Referências bibliográficas}

AJAYL, S.A.; WILSON, A.J.; CAMPBELL, R.S.F. Experimental bovine anaplasmosis: clinico-pathological and nutritional studies. Res. Vet. Sci., v. 25, p. 76-81, 1978.

BANGEL JUNIOR., J.J.; SCHEFFER, A.L.; DIAS, M.M. Premunição de bovinos segura e sem perdas. Arq. Fac. Vet. UFRGS, v. 15, p. 5-9, 1987.

BLOOD, D.C., RADOSTITS, O.M. Clínica Veterinária. 7 ed.Rio de Janeiro. Ed. Guanabara Koogan, 1991, 1.263 p.

BRASIL, A.G. Premunição contra a tristeza parasitária em bovinos a campo. A Hora Vet., v. 2, n. 10, p. 4-8, 1982.

CALLOW, L.L. \& PEPPER, P.M. Measurement of and correlations between fever, changes in the packed cell volume and parasitaemia in the evaluation of the susceptibility of cattle to infection with Babesia argentina. Aust. Vet. J., v. 50, n. 1, p. 1-5, 1974.

CORRÊA, W.M., CORRÊA, C.N.M. Enfermidades infecciosas dos mamíferos domésticos. 2. ed. Rio de Janeiro: Ed. Medsi, 1992, 843 p.

EMERSON, F.R.; KNOTT, S.G.; McGREGOR, W. Tick fevers - and how to prevent them. Queensland Agr. J., v. 100, n. 9, p. 405-416, 1974.

ESTRADA PEÑA, A. Babesiosis: diagnóstico, tratamiento,inmunización y epizootiología. Med. Vet., v. 1,n. 2, p. 7-16, 1984.

GONZÁLES, E.F.; TODOROVIC, R.A; THOMPSON, K.C. Immunization against anaplasmosis and babesiosis: Part I. Evaluation of immunization using minimum infective doses under laboratory conditions. Tropenmed. Parasit., v. 27,n. 3, p. 427-437, 1976. não haver parasitemia por $A$. marginale, diferindo dos resultados encontrados por Loss (1991).

A prova de imunofluorescência indireta (IFA) se mostrou eficiente na comprovação de anticorpos contra $B$. bigemina, $B$. bovis e A. marginale em acordo com Ross e Lohr (1968) e Estrada Peña (1984).

Assim sendo, verificou-se que os inóculos para $B$. bigemina e $B$. bovis mostraram-se eficientes na indução da infecção e da imunidade nos animais inoculados, além de apresentarem uma baixa patogenicidade, sendo uma boa opção para premunição.

Da mesma forma, o inóculo para A. marginale foi eficiente na indução da imunidade, porém ainda requer um acompanhamento clínico intenso dos animais inoculados devido à sua patogenicidade.

Já o acompanhamento do volume globular e da percentagem de parasitemia são fundamentais para realização de uma premunição segura e eficiente.

Com relação ao tratamento da babesiose durante a premunição, ele deve ser iniciado logo que se constate $B$. bigemina no esfregaço sangüíneo, acompanhado de outros sintomas como aumento da temperatura e queda do volume globular. Entretanto, o tratamento da anaplasmose deve ser iniciado a partir do momento em que a percentagem de hemácias parasitadas ultrapasse $1 \%$, a fim de se evitar mortalidade.

Finalmente, concluiu-se que na maioria dos casos, a parasitemia por $A$. marginale pode aumentar, mesmo após iniciado o tratamento com oxitetraciclina, diminuindo em média dois a quatro dias após.

HANSARD, S.L., FOOTE, L.E. Anemia of induced anaplasmosis in the calf. Am. J. Physiol., v. 197,n. 1, p. 711-716, 1959.

JATKAR, P.R., KREIER, J.P. Pathogenesis of anemia in anaplasma infection. Indian Vet. J., v. 44, n. 5, p. 393-399, 1964.

KOHAYAGAWA, A. Estudo clínico e laboratorial do desenvolvimento da premunição contra Babesia e Anaplasma em bovinos (Bos taurus) da raça Fleckview. 1985, 117p. Tese (Doutorado) - Botucatu, Faculdade de Medicina Veterinánia e Zootecnia da Universidade Estadual Paulista.

KREIER, J.P.; RISTIC, M.; SCHROEDER, W. Anaplasmosis. XVI. The pathogenesis of anemia produced by infection with anaplasma. Am. J. Vet. Res., v. 25, n. 1, p. 343-352, 1964.

KREIER, J.P. ed. Parasitic Protozoa. v. 4, New York: Academic Press, 1977. $221 \mathrm{p}$.

LOSS, A.C.S. Avaliação do curso da infecção e da resposta humoral para Anaplasma marginale (Theiler, 1910) em bovinos submetidos ao processo de premunição. 1991, 67 p. Tese (Mestrado) Belo Horizonte, Universidade Federal de Minas Gerais.

MASSARD, C.L. Sanidade animal: tristeza parasitária dos bovinos. $A$ Hora Vet., n. 54, p.10-13, 1990.

OTIM, C.; WILSON, A.J.; CAMPBELL, R.S.F. A comparative study of experimental anaplasmosis in Bos indicus and Bos taurus cattle. Aust. Vet. J., v. 56, p. 262-266, 1980.

PANDEY, N.N., MISHA, S.S. Studies on the clinical symptoms and percentage of parasitaemia in experimental Babesia bigemina infection in cow calves. Indian Vet. J., v. 55, p. 139-143, 1978.

ROSS, J.P.J., LOHR, K.F. Serologic diagnosis of Babesia bigemina infection in cattle by the indirect fluorescent antibody test. Res. Vet. Sci., n. 1,v. 9, p. 557-562, 1968. 
SANTOS, J.A. Normas práticas para a premunição de bovinos contra a tristeza parasitária (piro e anaplasmose). Instituto de Biologia Animal, 1950, $10 \mathrm{p}$.

STEPHAN, O., SQUIBEL, A. Método de premunição contra a tristeza, usado no Posto Zootécnico de São Paulo. Arq. Inst. Biol., São Paulo, v. 2, n. 1, p. 183-208, 1929.
TODOROVIC, R.A. Serological diagnosis of babesiosis: A Review. Trop. Anim. Health and Prod., v. 7, n. 1, p. 1-14, 1975.

TODOROVIC, R.A., TELLEZ, C.H. The premunition of adult cattle against babesiosis and anaplasmosis in Colombia, South America. Trop. Anim. Hith. Prod., v. 7, n. 1, p. 125-131, 1975.

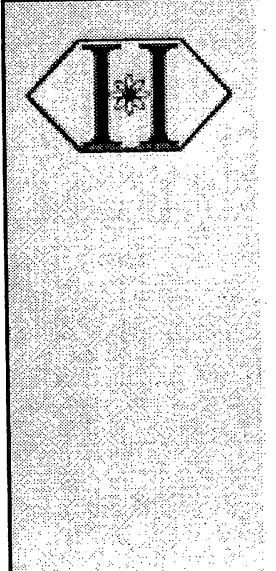

\title{
HEXÁGONO QUÍMICA E EQUIPAMENTOS PARA LABORATÓRIOS LTDA.
}

\author{
( Distribuidor MERCK, VWR, WTW, BRAND )
}

RUA DAS OFICINAS, 167 - ENGENHO DE DENTRO - CEP 20770-010

FAX: (21) 595-6055 - PABX: (21) 597-1231 